\title{
Capacitation status of hamster spermatozoa in the oviduct at various times after mating
}

\author{
T. T. Smith and R. Yanagimachi \\ Department of Anatomy and Reproductive Biology, University of Hawaii School of Medicine, \\ 1960 East-West Road., Honolulu, Hawaii 96822, USA
}

\begin{abstract}
Summary, Female hamsters were mated shortly after the onset of oestrus or immediately after ovulation. At various times after mating, spermatozoa were flushed from the isthmus of the oviduct using a modified Tyrode's medium supplemented with $20 \%$ hamster serum. Cumulus oophorus-free eggs were introduced into the suspensions of isthmic spermatozoa. Some eggs were removed every $30 \mathrm{~min}$ and examined for evidence of fertilization. For females mated shortly after the onset of oestrus, spermatozoa recovered from the oviducts $8 \mathrm{~h}$ after mating (about $1.5 \mathrm{~h}$ after ovulation) could penetrate eggs within $30 \mathrm{~min}$ and were considered fully capacitated. When spermatozoa were recovered at earlier times (1,2, 4 and $6 \mathrm{~h}$ after mating) they required additional time $(2,1 \cdot 5,1$ and $1 \mathrm{~h}$ respectively) in vitro before penetrating eggs. Therefore, when mating occurs shortly after the onset of oestrus, spermatozoa in the oviduct do not appear to become fully capacitated until about the time of ovulation. For females mated immediately after ovulation, spermatozoa recovered from the oviducts at $4 \mathrm{~h}$ after mating could penetrate eggs within $30 \mathrm{~min}$. Spermatozoa recovered at 1 and $3 \mathrm{~h}$ after mating required 2 and $1 \mathrm{~h}$ respectively in vitro before penetrating eggs. These results suggest that sperm capacitation proceeds at a faster rate when mating occurs after ovulation.
\end{abstract}

Keywords: capacitation; spermatozoa; female genital tract; hamster

\section{Introduction}

In all eutherian mammals studied to date, spermatozoa must reside in the female reproductive tract for some time before they become capable of fertilizing eggs; a process called 'capacitation' (Chang, 1951; Austin, 1951) (for review, see Yanagimachi, 1988). The site within the female tract where capacitation begins may vary depending on species. For those species in which semen enters the uterus upon ejaculation (e.g. most laboratory rodents and the pig), capacitation may begin in the uterus or shortly after spermatozoa enter the oviduct. When a female hamster mates shortly after the onset of oestrus, thousands of spermatozoa enter the lower segments (intramural and caudal isthmus) of the oviduct within $1 \mathrm{~h}$ of mating (Yanagimachi \& Chang, 1963; Smith et al., 1987). These spermatozoa do not advance beyond the lower segments in significant numbers until the time of ovulation, when a relative few advance to the ampulla to effect fertilization (Smith et al., 1987). This implicates the lower segments of the oviduct as the site for sperm capacitation in the hamster. The question arises as to when these spermatozoa become capacitated. At least two possibilities exist. Either these spermatozoa become capacitated shortly after entering the isthmus or they remain uncapacitated until ovulation commences.

In a previous study (Smith et al., 1987) we reported that, when female hamsters were mated near the time of ovulation, the vast majority of oviducal spermatozoa remained in the isthmus for a minimum of $3 \mathrm{~h}$ before advancing to the ampulla to effect fertilization. This may represent the 
minimum capacitation time for hamster spermatozoa in vivo. The time required for capacitation in vivo may depend on the time of mating. It is possible that sperm capacitation requires less time when mating occurs after ovulation than when mating occurs shortly after the onset of oestrus. The purpose of this study was to determine when the spermatozoa in the isthmus become fully capacitated and whether the time required for sperm capacitation is influenced by the time of mating.

\section{Materials and Methods}

Animals. The mature female golden hamsters (7-10 weeks old) used in this study were born and raised to weaning in an air conditioned room with controlled light conditions (light 05:00-19:00 h; dark 19:00-05:00 h). At weaning, up to 6 females were housed together in a large cage $(30 \times 35 \times 17 \mathrm{~cm})$ and transferred to a cabinet with reversed light conditions (light 17:00-07:00 h; dark 07:00-17:00 h) and allowed to mature for at least 4 weeks. Under this light regimen, mature females come into oestrus by $06: 30 \mathrm{~h}$ of every 4th day, ovulate between 12:30 and 13:30 h and ext bit a post-ovulatory vaginal discharge by 18:00 $\mathrm{h}$ of the same day. After reaching maturity, females were checked in the evening for 4 consecutive days for the presence of a post-ovulatory discharge (Orsini, 1961). The day of the postovulatory discharge (the day of ovulation) was designated Day 1 of the oestrous cycle. After determination of the oestrous cycle, each female was then housed individually in a smaller cage $(20 \times 26 \times 15 \mathrm{~cm})$. Mature males (16-24 weeks old) of proven fertility used for mating were housed as sibling pairs in large cages $(30 \times 35 \times 17 \mathrm{~cm})$. Males used in this study were raised and kept in an air conditioned room with the regular light regimen (light 05:00-19:00 h, dark 19:00-05:00 h).

Collection of eggs. Mature females were each injected intramuscularly with 20-30 i.u. PMSG (Calbiochem, La Jolla, CA, USA) in the afternoon or evening of Day 1 followed by 20-25i.u. hCG (Ayerst, New York, NY, USA) $50-56 \mathrm{~h}$ later. Oviducts were removed $18 \mathrm{~h}$ after hCG injection and a cumulus mass containing 20-30 eggs was recovered by flushing each oviduct with about $100 \mu \mathrm{lm}$-TALP-7 medium (pH 7.4) (Uto et al., 1988). Cumuli were transferred to Medium m-TALP-7 containing $0 \cdot 1 \%$ bovine testicular hyaluronidase (ICN Biochemicals, Cleveland, $\mathrm{OH}$, USA; 300 U.S.P. units $/ \mathrm{mg}$ ) to dissolve the cumulus matrix surrounding the eggs. The cumulus-free eggs were rinsed twice in Medium m-TALP-7 and kept at $38^{\circ} \mathrm{C}$ in Medium m-TALP-7 supplemented with $20 \%$ heat-treated $\left(60^{\circ} \mathrm{C}, 30 \mathrm{~min}\right)$ hamster serum for less than $30 \mathrm{~min}$ before insemination. Serum was collected from males and from females in all stages of the oestrous cycle and pooled before heat treatment. Since the serum raised the $\mathrm{pH}$ of the medium, the $\mathrm{pH}$ was adjusted to 7.4 by adding a small quantity of $0.1 \mathrm{M}-\mathrm{HCl}$. It was important to keep the medium under mineral oil (Squibb \& Sons, Princeton, NJ, USA) to maintain this slightly alkaline pH. The pH of this medium, when covered with mineral oil, was stable $(7 \cdot 4-7.5)$ under pure air $\left(38^{\circ} \mathrm{C}\right)$ for up to $8 \mathrm{~h}$.

Mating. An oestrous female (Day 1) was introduced into the large cage of a sibling pair of males at $07: 00 \mathrm{~h}(5 \cdot 5 \mathrm{~h}$ before the onset of ovulation) or 14:00 $\mathrm{h}$ (shortly after ovulation was completed). In this paper, these will be referred to as early mating and late mating respectively. Mating (intromissions) began within 2-5 min. Each female was allowed to remain in the males' cage until just before sperm collection.

Collection of spermatozoa and insemination of eggs. At various times $(1-8 \mathrm{~h})$ after the onset of mating, females were killed by inhalation of $100 \% \mathrm{CO}_{2}$ (about $45 \mathrm{sec}$ ) and immediately placed in a $38^{\circ} \mathrm{C}$ operating chamber. All subsequent steps were carried out at $38^{\circ} \mathrm{C}$; all instruments, equipment, media and mineral oil were warmed to $38^{\circ} \mathrm{C}$ before use. Oviducts were removed from females with care being taken to include the first loop of the extramural oviduct which adheres to the outside of the uterine apex. Each oviduct was rinsed in Medium m-TALP-7, blotted on filter paper to remove any blood and then placed in a watchglass containing mineral oil. A 30-gauge needle attached to a 50- $\mu$ l glass syringe was inserted into the infundibulum and $20 \mu \mathrm{l}$ Medium m-TALP-7 with $20 \%$ hamster serum were gently flushed through the oviduct. Immediately after flushing, the oviduct was transferred to another watchglass containing mineral oil. About 3 min later, an additional $20 \mu$ l Medium m-TALP-7 with $20 \%$ serum were flushed through the oviduct. When spermatozoa were to be recovered from the oviducts of ovulated females, each isolated oviduct was cut at the ampullary-isthmic junction. The needle was inserted into the cephalic isthmus and only the isthmic region was flushed. This ensured that the recovered spermatozoa had not previously come into contact with the cumulus oophorus or eggs. The first and second flushes of each oviduct were examined and the flush containing the greater number of motile spermatozoa was used for insemination.

Insemination was performed by introducing 20-30 cumulus-free eggs into the oviducal flush under mineral oil in the watchglass. Incubation was carried out at $38^{\circ} \mathrm{C}$. At $30 \mathrm{~min}$ intervals, 5-10 eggs were removed from the watchglass and examined for evidence of fertilization. Eggs were considered fertilized when a sperm head was seen to have begun decondensation in the ooplasm. When sperm-egg fusion was suspected, but decondensation was not yet apparent, the cortical granules of the ooplasm were examined (Austin, 1956). If the exocytosis of cortical granules was evident, the egg was considered fertilized. In addition, the acrosomal status of motile spermatozoa on the zona pellucida was determined at $30 \mathrm{~min}$ after insemination. Spermatozoa were scored as having an intact, modified or reacted acrosome (Uto et al., 1988).

A group of eggs were inseminated with ejaculated spermatozoa which had never resided in the oviduct. Semen was collected from the uteri of females $20-30 \mathrm{~min}$ after the onset of mating (unlike the rat uterus, the hamster uterus 
contains very little uterine fluid during the oestrous period, and so the spermatozoa collected from the uterus shortly after mating were in almost pure seminal plasma). Using a Pasteur pipette, about $20 \mu \mathrm{l}$ of the semen were carefully placed at the bottom of a short test tube $(15 \times 50 \mathrm{~mm})$ containing $2 \mathrm{ml}$ Medium m-TALP-7 with $20 \%$ hamster serum $\left(38^{\circ} \mathrm{C}\right)$ to allow the actively motile spermatozoa to swim up into the medium. After $1-2 \mathrm{~min}$, the upper $30 \mu \mathrm{l}$ of the medium were removed and the concentration of spermatozoa was adjusted to $\sim 1 \times 10^{5} \mathrm{cells} / \mathrm{ml}$. Then $20 \mu \mathrm{l}$ of this sperm suspension were placed in a watchglass and covered with mineral oil. Insemination and examination of the eggs were performed as already described.

Examination of eggs fertilized in vivo. Females were mated either shortly after the onset of oestrus $(5 \cdot 5-6 \cdot 5 \mathrm{~h}$ before ovulation) or shortly after ovulation was completed. At various times $(0.5-7.5 \mathrm{~h})$ after the end of ovulation, eggs were recovered by flushing the oviducts. The cumulus celis were removed and the eggs were examined for evidence of fertilization as previously described.

\section{Results}

Many (65-94\%) of the spermatozoa recovered in the first oviducal flush were immotile regardless of the time of recovery. Most spermatozoa were recovered as large agglutinated masses and did not regain their motility in the medium. In general, the second flush contained a higher proportion of motile spermatozoa (10-25\%), but the absolute number of spermatozoa was considerably less than that in the first flush. The second flush was usually used for insemination. The initial concentration of motile spermatozoa at insemination ranged from $2-6 \times 10^{3}$ cells $/ \mathrm{ml}(45-120$ spermatozoa/20 $\mu \mathrm{l})$. When Medium m-TALP-7 was used without serum supplement, most of the motile spermatozoa flushed from the oviduct died within $30 \mathrm{~min}$, indicating the fragile nature of these spermatozoa. When Medium m-TALP-7 was supplemented with $20 \%$ serum, a higher proportion of recovered spermatozoa remained alive during subsequent in-vitro incubation. A small proportion of the spermatozoa (about 1-2\%) recovered from the oviduct between 4 and $8 \mathrm{~h}$ after early mating exhibited hyperactivated motility (Yanagimachi, 1981). A similar proportion of spermatozoa exhibited hyperactivated motility in the medium when they were recovered from the oviduct $4 \mathrm{~h}$ after late mating.

Because of the relatively low motile sperm:egg ratio (less than 10:1), not all eggs were fertilized. However, most eggs had at least one spermatozoon attached within $5 \mathrm{~min}$ of insemination. At $30 \mathrm{~min}$ after insemination, $80-90 \%$ of the motile spermatozoa on the zonae pellucidae were acrosome-reacted when spermatozoa were recovered $8 \mathrm{~h}$ after early mating or $4 \mathrm{~h}$ after late mating. None of the spermatozoa underwent the acrosome reaction on the zonae within 30 min when they were recovered from the oviduct before these times.

Figure 1(a) shows the minimum time required for spermatozoa to fertilize eggs in vitro after being recovered from the oviduct following early mating. The spermatozoa that were recovered from the isthmus at $1 \mathrm{~h}$ after mating spent at least 2 more hours in the medium (on zonae) before fertilizing the eggs. The interval between insemination and the first eggs fertilized was 1.5 and $1 \mathrm{~h}$ when spermatozoa were recovered from the isthmus at 2 and $4-6 \mathrm{~h}$ after mating respectively. The spermatozoa collected from the isthmus $8 \mathrm{~h}$ after mating could fertilize eggs almost immediately (within $30 \mathrm{~min}$ ). Spermatozoa required less time in vitro to fertilize eggs when animals were mated immediately after ovulation (late mating) (Fig. 1b).

Freshly ejaculated spermatozoa (recovered from the uterus $20-30 \mathrm{~min}$ after the onset of mating) were not consistently able to fertilize eggs under the in-vitro conditions used in this study. Although initial motility was good ( $>95 \%)$, only about $50 \%$ were still motile and a few $(<1 \%)$ were hyperactivated at $3 \mathrm{~h}$ after the start of incubation. At $5 \mathrm{~h}$ after insemination, $<5 \%$ of the free swimming spermatozoa were motile. At this time, only about $20 \%$ of the spermatozoa on the zonae pellucidae were motile, the remainder being immotile and presumably dead. In spite of the fact that most of the motile spermatozoa on the zonae were acrosome reacted at $5 \mathrm{~h}$ after insemination, zona penetration and subsequent fertilization had occurred only rarely by this time ( $3 / 54$ eggs in 5 trials).

Figure 2 shows the progression of in-vivo fertilization following early and late matings. In females mated soon after the onset of oestrus (early mating), fertilization began at $7 \mathrm{~h}$ and was 


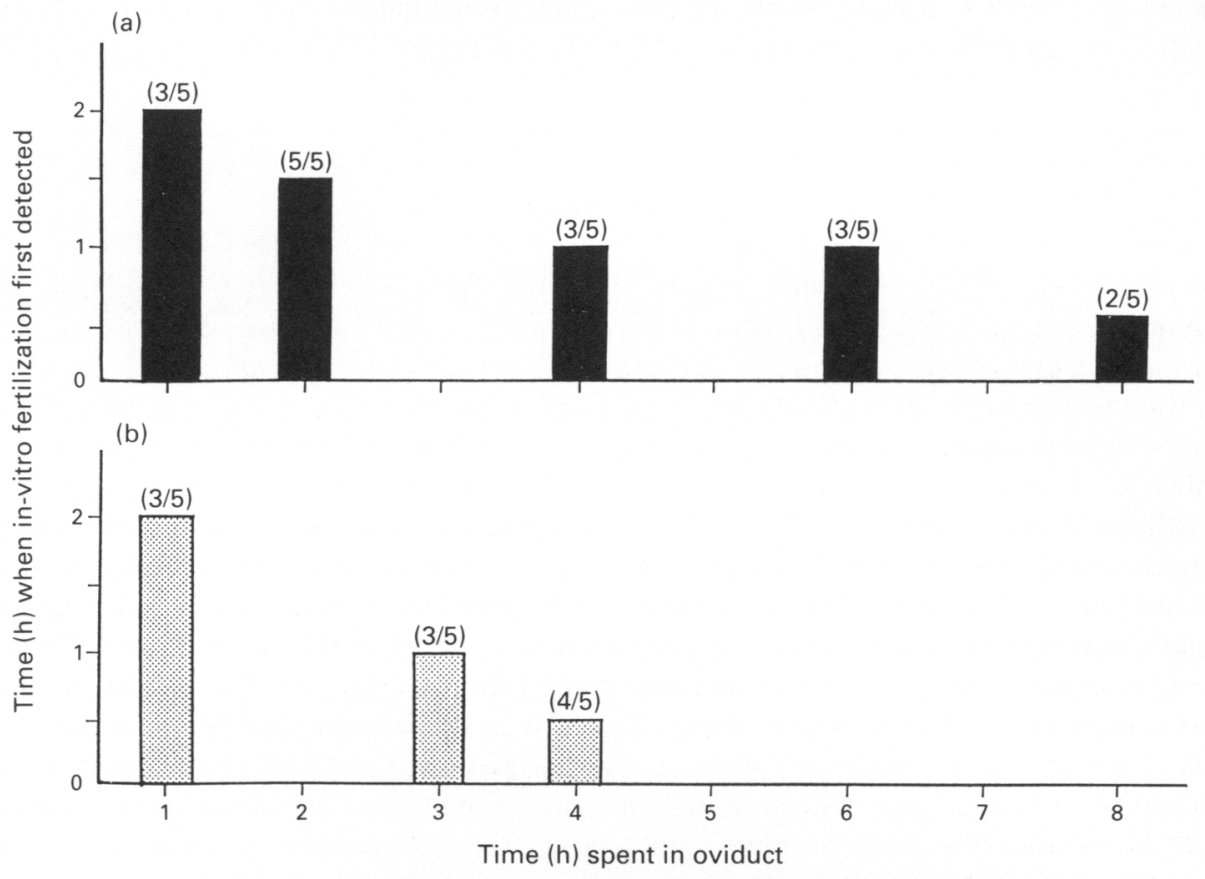

Fig. 1. Minimum time isthmic spermatozoa spend in vitro before fertilizing eggs. (a) Spermatozoa from females mated shortly after the onset of oestrus $(5.5-6.5 \mathrm{~h}$ before ovulation). (b) Spermatozoa from females mated immediately after ovulation. Data presented here represent 5 trials. Numbers in parentheses refer to the number of times in 5 trials that fertilization had occurred by the time indicated by the bar.

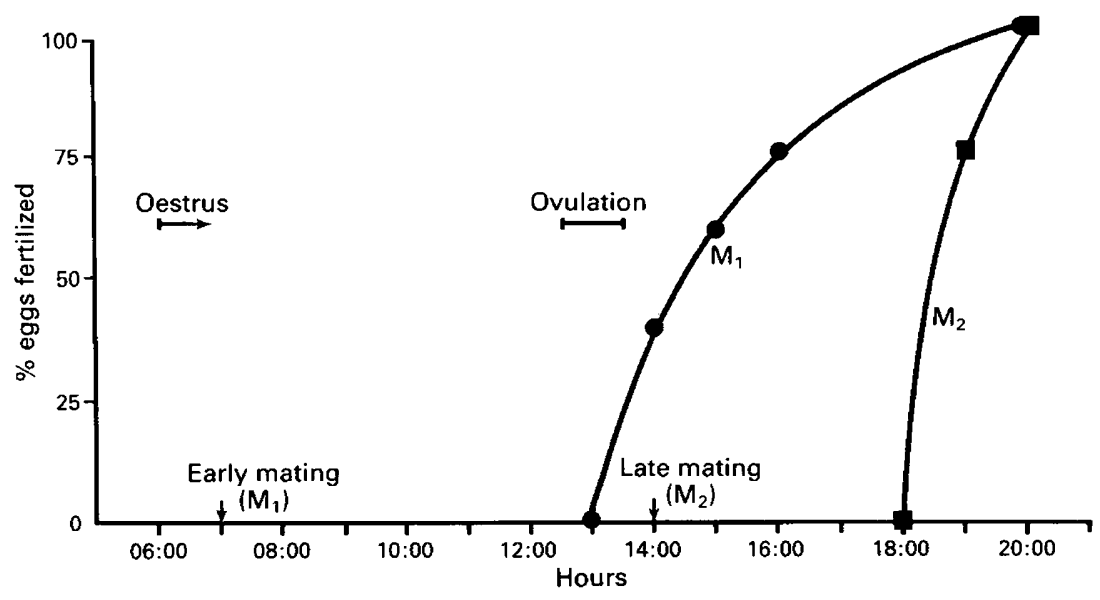

Fig. 2. The progression of fertilization in female hamsters mated shortly after the onset of oestrus $(07: 00 \mathrm{~h})$ or immediately after ovulation $(14: 00 \mathrm{~h})$. Each point represents the mean value obtained from 30-50 eggs (from 3-4 females) recovered from the oviduct for each time. 
completed by $13 \mathrm{~h}$ after mating. In the females mated immediately after ovulation (late mating), fertilization began some time between 4 and $5 \mathrm{~h}$ after mating and was completed within the next $2 \mathrm{~h}$.

\section{Discussion}

A large proportion of immotile spermatozoa were recovered from the oviduct regardless of the time of mating and sperm recovery. This does not appear to be an artefact of flushing. Many immotile spermatozoa were observed through the wall of the caudal isthmus of an uncompressed preparation of excised oviduct illuminated with strong transmitted light; large numbers of immotile spermatozoa were also observed in the contents of the isthmus which had been released directly into mineral oil on a slide glass (unpublished observations). The presence of immotile spermatozoa in the isthmus is not unique to the hamster. Immotile spermatozoa were seen in oviducal flushings of the rabbit isthmus (Overstreet \& Cooper, 1975; Burkman et al., 1984) and through the wall of the mouse isthmus (Suarez, 1987). The immotile hamster spermatozoa recovered from the isthmus did not regain their motility. Apparently they were dead or dying while they were in the isthmus. Since hamster spermatozoa must be actively motile to pass through the uterotubal junction and reach the isthmus (Smith et al., 1988), these spermatozoa must have died after reaching the isthmus. The fragility of the isthmic spermatozoa was evident when Medium m-TALP-7 without serum was used as the flushing medium; many or all of initially motile spermatozoa became motionless (presumably dead) within $30 \mathrm{~min}$. Hamster spermatozoa collected from the cauda epididymidis could survive well in Medium m-TALP-7 without serum (Uto et al., 1988). This was also true for hamster spermatozoa recovered from semen (unpublished observations). Therefore, it appears that spermatozoa become unadaptable to this serum-free medium once they have been exposed to the oviduct milieu. Some serum components added to the medium seem to rescue flushed isthmic spermatozoa from death.

Capacitation was assessed by determining how quickly flushed isthmic spermatozoa could fertilize eggs in vitro. If the spermatozoa penetrated the eggs immediately or at least within $30 \mathrm{~min}$ after sperm-egg contact, they must have been fully capacitated before they were flushed. On the contrary, if spermatozoa penetrated the eggs only after they had been in the medium for some time, they must have been only partly capacitated. The results obtained indicate that when females are mated shortly after the onset of oestrus (early mating), capacitation proceeds steadily during the first $4 \mathrm{~h}$ and then stays at a plateau until it is completed at some time between 6 and $8 \mathrm{~h}$ after mating (Fig. 1a). Since the females in this group ovulated about $6 \mathrm{~h}$ after mating, we may conclude that the completion of capacitation (at least for some spermatozoa) is more or less synchronous with the appearance of eggs in the oviduct. The plateau in capacitation status which occurs between 4 and $6 \mathrm{~h}$ after mating could be due to a temporal arrest of capacitation until the time of ovulation. Alternatively, some essential factor for sperm capacitation may be missing from the oviducal milieu until about the time of ovulation. It is possible that the epithelium of the oviduct is triggered to produce the missing factor by the change in the oestrogen/progesterone ratio which occurs near the time of ovulation. Hunter (1987a) has suggested that, for species with a prolonged period between mating and ovulation (e.g. cow and pig), the timing of sperm capacitation in the oviduct is controlled by locally transmitted hormonal influences from Graafian follicles. In the hamster, the time between mating and ovulation is relatively short, but it is probable that the timing of sperm capacitation is controlled in a similar manner. When females were mated at about the time of ovulation (late mating), capacitation was completed at least in some spermatozoa by $4 \mathrm{~h}$ after mating (Fig. 1b). This means that capacitation proceeds twice as fast after late mating compared to early mating. The plateau in capacitation status observed following early mating was absent in this group of females. It would appear that the post-ovulatory oviduct milieu provides a more efficient environment for sperm capacitation. 
The time when isthmic spermatozoa begin to become fully capacitated after early and late mating (as determined by in-vitro fertilization) was coincident with the time of initiation of in-vivo fertilization (compare Figs 1 \& 2). It would appear that, as soon as isthmic spermatozoa become fully capacitated (6-8 h after early mating and $4 \mathrm{~h}$ after late mating), they begin to advance to the ampulla to effect fertilization.

The medium used (m-TALP-7 with $20 \%$ serum) did not consistently support fertilization by spermatozoa obtained from semen. These spermatozoa could undergo the acrosome reaction on the zonae pellucidae of the eggs, but seldom penetrated the zonae. On the other hand, the spermatozoa collected from the isthmus penetrated the zonae consistently. These facts suggest that spermatozoa change their characteristics soon after entering the oviduct. This change could represent the first step of capacitation in vivo.

Spermatozoa which are about to fertilize eggs in the ampulla are hyperactivated and ready to undergo the acrosome reaction (Cummins \& Yanagimachi, 1982). A small proportion of spermatozoa recovered from the isthmus $4 \mathrm{~h}$ after early mating displayed hyperactive movement when they were flushed out of the isthmus. We are unable to say whether these spermatozoa were hyperactivated within the isthmus, but they certainly had the potential for hyperactivation. Hyperactivated movement of mouse spermatozoa was observed in the isthmus $1-2 \mathrm{~h}$ after mating (Suarez \& Osman, 1987). At least in the hamster and mouse, the vigorous whiplash-like beatings of the tail, characteristic of this type of movement, may assist the spermatozoon in changing direction and escaping from the epithelial pockets of the isthmus and thereby assist it in its advance towards the ampulla.

All motile spermatozoa recovered from the isthmus had apparently intact acrosomes. They were able to attach to the zonae pellucidae, but were unable to undergo the acrosome reaction within $30 \mathrm{~min}$ except for those spermatozoa that had resided in the isthmus for $8 \mathrm{~h}$ (after early mating) or $4 \mathrm{~h}$ (after late mating). These data also support the contention that capacitation is completed faster in females mated shortly after ovulation than in those mated shortly after the onset of oestrus.

A minimum capacitation time of 3-4 h for hamster spermatozoa following mating after ovulation was determined by indirect methods in previous studies (Strauss, 1956; Yanagimachi, 1966; Smith et al., 1987). The result of this study provides direct evidence to support this. However, depending on when mating occurs, the minimum time may not be the actual time required for capacitation. Indeed, as Hunter (1987b) has pointed out, for species in which mating occurs many hours before ovulation, there would be little value for spermatozoa to become capacitated within a few hours after ejaculation since capacitated spermatozoa are fragile, short-lived cells and would be non-functional by the time of ovulation. From the data presented here, it appears that the oviduct is capable of controlling the timing of sperm capacitation in order to synchronize the physiological state of the gametes and thereby maximize fertilization. The mechanism by which the oviduct performs this function in the hamster will be the subject of future studies.

This study was supported by a grant from the National Institutes of Health (HD 03402).

\section{References}

Austin, C.R. (1951) Observations on the penetration of the sperm into the mammalian egg. Aust. J. Sci. Res. (B) 4, 581-596.

Austin, C.R. (1956) Cortical granules in hamster eggs. Expl Cell Res. 10, 553-540.

Burkman, L.J., Overstreet, J.W. \& Katz, D.F. (1984) A possible role for potassium and pyruvate in the modulation of sperm motility in the rabbit oviductal isthmus. J. Reprod. Fert. 71, 367-376.
Chang, M.C. (1951) Fertilization capacity of spermatozoa deposited in the Fallopian tubes. Nature, Lond. 168, 997-998.

Cummins, J.M. \& Yamagimachi, R. (1982) Sperm-egg ratios and the site of the acrosome reaction during in vivo fertilization in the hamster. Gamete Res. 5, $239-256$.

Hunter, R.H.F. (1987a) Peri-ovulatory physiology of the oviduct, with special reference to progression, 
storage, and capacitation of spermatozoa. In New Horizons in Sperm Cell Research, pp. 31-45. Ed. H. Mohri. Breach Scientific Publishers, New York.

Hunter, R.H.F. (1987b) The timing of capacitation in mammalian spermatozoa-a reinterpretation. Res. Reprod. 19 (2), 34.

Orsini, M.W. (1961) The external vaginal phenomena characterizing the stages of the estrous cycle, pregnancy, pseudopregnancy, lactation, and the anestrous hamster Mesocricetus auratus waterhouse. Proc. Anim. Care Panel 11, 193-206.

Overstreet, J.W. \& Cooper, G.W. (1975) Reduced sperm motility in the isthmus of the rabbit oviduct. Nature, Lond. 258, 718-719.

Smith, T.T., Koyanagi, F. \& Yanagimachi, R. (1987) Distribution and number of spermatozoa in the oviduct of the golden hamster after natural mating and artificial insemination. Biol. Reprod. 37, 225-234.

Smith, T.T., Koyanagi, F. \& Yanagimachi, R. (1988) Quantitative comparison of the passage of homologous and heterologous spermatozoa through the uterotubal junction of the golden hamster. Gamete Res. 19, 227-234.

Strauss, F. (1956) The time and place of fertilization of the golden hamster egg. J. Embryol. exp. Morph. 4, $42-56$.
Suarez, S.S. (1987) Sperm transport and motility in the mouse oviduct: Observations in situ. Biol. Reprod. 36, 203-210.

Suarez, S.S. \& Osman, R.A. (1987) Initiation of hyperactivated flagellar bending in mouse sperm within the female genital tract. Biol. Reprod. 36, 1191-1198.

Uto, N., Yoshimatsu, N., Lopata, A. \& Yanagimachi, R. (1988) Zona-induced acrosome reaction of hamster spermatozoa. J. exp. Zool. 248, 113-120.

Yanagimachi, R. (1966) Time and process of sperm penetration into hamster ova in vivo and in vitro. $J$. Reprod. Fert. 11, 359-370.

Yanagimachi, R. (1981) Mechanisms of fertilization in mammals. In Fertilization and Embryonic Development In Vitro, pp. 81-82. Eds L. Mastroianni \& J. D. Biggers. Plenum Publishing Corp., New York.

Yanagimachi, R. (1988) Mammalian fertilization. In The Physiology of Reproduction, pp. 135-185. Eds E. Knobil \& J. D. Neill. Raven Press, Ltd, New York.

Yanagimachi, R. \& Chang, M.C. (1963) Sperm ascent through the oviduct of the hamster and rabbit in relation to the time of ovulation. J. Reprod. Fert. 6, $413-420$.

Received 30 August 1988 